\title{
Analysis of BLOCK OF CELL PROLIFERATION 1 (BOP1) activity in strawberry and Arabidopsis
}

Sofia D. Carvalho ${ }^{1+}$, Mithu Chatterjee ${ }^{1+}$, Lauren Coleman ${ }^{1}$, Maureen A. Clancy ${ }^{1}$, Kevin M. Folta ${ }^{1,2^{*}}$

${ }^{1}$ Horticultural Sciences Department, University of Florida, Gainesville, FL USA

${ }^{2}$ Plant Molecular and Cellular Biology Program, University of Florida, Gainesville, FL USA

${ }^{\dagger}$ Authors contributed equally to this work

${ }^{*}$ Corresponding Author:

Kevin M. Folta

Horticultural Sciences Department

1301 Fifield Hall, University of Florida

Gainesville, FL 32611

kfolta@ufl.edu

352-273-4812

Running Head: Functional analysis of BOP1 in plants 


\begin{abstract}
BLOCK OF CELL PROLIFERATION (BOP) proteins are conserved among eukaryotes, and studies in mammals and yeast have described their role in ribosome biogenesis and cell cycle regulation. A BOP1 orthologue was identified in plants, and loss-of-function analyses in tobacco cells confirmed similar activities. This report characterizes role for BOP1 activity in planta. Two transgenic plant species were used, the diploid strawberry (Fragaria vesca) and Arabidopsis thaliana. FvBOP1 silencing showed changes in pre-rRNA processing, and demonstrated FVBOP1's role on growth and physiology throughout different stages of plant development. In the strawberry, repression of FVBOP1 activity decreases plant fitness prior to flowering, followed by plant death after the reproductive transition, indicating that BOP1 activity is required for transition back to vegetative growth after flowering. A T-DNA null allele of the AtBOP1 gene is lethal, and a $50 \%$ decrease in transcript accumulation is sufficient to cause severe developmental defects linked to defective cell division. The conserved protein BOP1 is essential for viability. Lower transcript levels result in defects in rRNA processing and developmental abnormalities that are consistent with its predicted role in ribosome biogenesis.
\end{abstract}

\title{
Keywords
}

Block of Cell Proliferation; Strawberry; Arabidopsis; rRNA processing; Cell cycle 


\section{Introduction}

Ribosomes are complexes of RNA and proteins that represent the site for protein synthesis. Ribosome biogenesis is tightly linked to cell division [1, 2], and occurs primarily in the nucleolus by a controlled mechanism involving the regulated activity of more than 200 proteins $[3,4]$. Ribosomal RNA gene transcription, pre-rRNA cleavage and processing, and mature rRNA association with ribosomal proteins lead to the assembly of the two ribosomal subunits, named $60 \mathrm{~S}$ and $40 \mathrm{~S}$ in eukaryotes [3]. Yeast has been the preferred model to unravel the molecular mechanisms supporting ribosome biogenesis [3]. Studies in other species, genomic sequences analyses, and proteomic approaches have further revealed that this process is conserved throughout eukaryotes, although few studies have focused on plants $[5,6]$.

Ribosomal proteins regulate various biological activities including cell proliferation, differentiation, apoptosis and other cellular processes [7]. Disturbances of ribosome biogenesis may result in developmental abnormalities. In humans, many diseases, including various types of cancer, result from defective activities of ribosomal proteins [7]. In yeast, cell cycle arrest and apoptosis have been reported to be caused by impaired ribosome assembly [3].

BLOCK OF CELL PROLIFERATION 1 (BOP1) was first isolated from a mouse, and truncation of the full length protein led to cell cycle arrest [8]. BOP1 has since been characterized as a conserved protein across eukaryotes, and has been shown to contribute to ribosome biogenesis and cell cycle progression in a variety of animals and fungi. BOP1 is recognized as Erb1p in yeast $[2,9,10]$. BOP1 plays a role in formation of the mature $28 \mathrm{~S}$ and $5.8 \mathrm{~S}$ rRNAs molecules and the biogenesis of the $60 \mathrm{~S}$ ribosomal subunit $[1,9,10]$, and consequently acts during cell division at $G_{1}$ checkpoints $[1,2]$. Other reports have described BOP1 activities that are tightly linked to mitosis, such as assuring chromosomal stability and correct segregation [11-13]. Impaired BOP1 activity results in dramatic phenotypes. Deregulated BOP1 activity has been associated with increased progression of liver or colorectal cancers, suggesting its use as an oncogenic marker $[11,14]$.

The BOP1 conserved structure is characterized by the presence of two regions: the BOP domain, responsible for correct subcellular localization to the nucleolus, and a number of WD40 repeats, involved in protein-protein interaction [9]. Two important factors that interact with BOP1 are PESCADILLO (PES or yeast Nop7p) and WDR12 (yeast Ytm1p), and the three proteins form the PeBoW 
complex [15-17]. This complex regulates rRNA processing, ribosome biogenesis, and cell proliferation $[15,18,19]$.

In plants, BOP1 was identified as an interacting partner with two components of the PeBoW complex. BOP1 from Arabidopsis thaliana (AtBOP1) was found to localize to the nucleolus when expressed in Nicotiana benthamiana cells. It interacts with AtPES and AtWDR12, and associates with ribosomes, particularly the 60S large subunit [20]. Transient silencing of BOP1 in tobacco resulted in defective ribosome biogenesis and strong reduction in protein synthesis, altered nucleoli structures, delayed cell growth and abnormal leaf development, phenotypes similar to the ones observed in PES and WDR12-silenced lines [20].

The present work details identification and characterization of BOP1 in stable strawberry and Arabidopsis transgenic lines. The transcript was first identified as a novel sequence in an octoploid strawberry (Fragaria $x$ ananassa) flower cDNA library. The function was examined using silencing in the diploid strawberry. These RNAi suppression lines displayed defects in leaf development, flower fertility, and rRNA processing. The effects of lower transcript levels were also examined in Arabidopsis. The results demonstrate the conserved activity of BOP1, and pleiotropic effects across plant growth and development. 


\section{Materials and methods}

\subsection{Plant materials and growth conditions}

Strawberry (Fragaria vesca Hawaii-4) seeds were surface sterilized with a $35 \%(\mathrm{v} / \mathrm{v})$ bleach solution for $20 \mathrm{~min}$, rinsed once with $70 \%$ ethanol and 3 times with water, and plated on horizontal plates with MS media ( $1 \times$ MS salts, $0.5 \mathrm{~g} \mathrm{l}^{-1} \mathrm{MES}, 1 \%$ sucrose, $0.7 \%$ agar, $\mathrm{pH} 5.7$ ) The seeds were stratified for $72 \mathrm{~h}$ at $4^{\circ} \mathrm{C}$ under darkness before being transferred to continuous white light. Six week-old seedlings were transferred to the same medium in magenta boxes, and maintained for transformation, or transferred to soil and to a growth chamber $22^{\circ} \mathrm{C}$ with a photoperiod of $8 \mathrm{~h}$ light/16h dark.

Arabidopsis (Arabidopsis thaliana Col-0) T-DNA lines were obtained from the SALK Institute and the GABI-Kat collections [21]. Seeds were surface sterilized with a $50 \%(v / v)$ bleach solution, $0.05 \%$ Tween20, for $10 \mathrm{~min}$, washed 3 times with water, and plated on MS media ( 1 x MS salts, $0.5 \mathrm{~g} \mathrm{I}^{-1} \mathrm{MES}, 0.1 \mathrm{~g} \mathrm{I}^{-1}$ myo-inositol, $0.8 \%$ agar, $\mathrm{pH}$ 5.7). The seeds were stratified at $4^{\circ} \mathrm{C}$ for $72 \mathrm{~h}$ under darkness before being transferred to a growth chamber at $22^{\circ} \mathrm{C}$ with a photoperiod of $16 \mathrm{~h}$ light/ $8 \mathrm{~h}$ dark. After 2 weeks the seedlings were transferred to soil and kept under the same environmental conditions.

\subsection{Isolation of FVBOP1}

A partial FaBOP1 transcript was isolated by random Sanger sequencing of cDNA clones from a Fragaria $x$ ananassa (cv. Strawbery Festival) library, prepared from combined flowers harvested from various developmental states. The full-length sequence of FvBOP1 was obtained from F. vesca Hawaii-4 by RTPCR amplification using the primers indicated in Table S1. The sequence of the cDNA clones are available in Genbank (XM_011466866.1). The genomic sequence was obtained from the $F$. vesca genome database ([22]; strawberrygenome.org).

\subsection{Subcellular localization of FvBOP1}

For localization experiments in tobacco, the full-length of FVBOP1 was cloned into the Gateway vectors pB7WGF2 and pB7FWG2, for N- and C-terminal GFP fusions, respectively. Agrobacterium tumefaciensmediated tobacco leaf infection in Nicotiana benthamiana was performed as described [23]. Images of GFP fusion protein localization were obtained with a Leica TCS SP5 broadband confocal laser-scanning microscope (Leica Microsystems).

\subsection{Phylogenetic analysis and accession numbers}


Phylogenic clustering was performed based on the neighbor-joining method [24] with the MEGA4 software [25]. Bootstrap values were based on 1000 replicates [26]. The following accession numbers were used: MmBOP1, NP_038509; HsBOP1, BAA09473; XIbop1-B, NP_001080358.1; DmBOP1, Q7K0Y1; CeY48B6A, Y48B6A.1; Erb1p, NP_013764; NcBOP1, XP_330757.1; AtBOP1, AAD25679; OsBOP1, BAC84089; CrBOP1, A8ID74. Strawberry BOP1, FvBOP1, has been registered in GenBank with KR092314.

\subsection{RNA isolation, Gel blot analysis and real-time qPCR}

For strawberry, total RNA was isolated from different tissues using a modification to a CTAB-based method [27]. Arabidopsis RNA was extracted from 1 week-old seedlings using the RNeasy Mini Kit (Qiagen). One g of DNAse treated RNA was used for cDNA synthesis using the ImProm-II Reverse Transcriptase (Promega). RNA gel-blot analyses were performed as described, using a Strawberry $18 \mathrm{~S}$ rDNA for a loading control [28].

The primers used for qPCR analyses are listed in Table S1. The internal controls were FvCHP1 for strawberry [29], and EF1 $\alpha$ and $U B 10$ for Arabidopsis. The $C_{T}$ for all genes were normalized to the internal controls and relative expression levels determined using the $C_{T}$ method. Error bars (Fig. 2 and Fig. $6 C)$ represent standard errors of the mean $(n=3)$. Results are representative of two independent experiments.

\subsection{Generation of strawberry RNAi lines and isolation of Arabidopsis T-DNA mutant plants}

The sequence specific to the FVBOP1 target region was cloned into the binary Gateway vector pK7GWIWG2D(II) [30] with standard LR Clonase II reaction conditions (Invitrogen). This construct was introduced intro Agrobacterium tumefaciens strain GV301 by electroporation. Stable transformation of Fragaria vesca was then performed using a slight modification to a published protocol [31], and transgenic plants were regenerated in vitro as previously described [32].

Arabidopsis T-DNA lines were genotyped at 2 to 4 weeks of age, using a small leaf from the rosette. Total DNA was extracted based on described protocols [33,34]. The primers used for genotyping are listed in Table S1.

\subsection{Anthocyanin measurements}

Strawberry leaves and petioles from the wild-type and three independent lines Fvbop1 RNAi lines were used for anthocyanin estimation. Anthocyanins were extracted and measured as described [35]. 


\subsection{Analysis of Arabidopsis siliques and gametogenesis}

To assess seed lethality, siliques from soil-grown plants were collected and dissected with a needle under a microscope. To assess effects on gametogenesis, reciprocal crosses were performed between the wild-type (WT, +/+) and the heterozygous Atbop1-2 (+/-). Eight siliques were collected from crossing Atbop1-2 $q \mathrm{x}, \mathrm{WT} \delta$ and nine were collected from the WT $q$ x Atbop1-2 $\widehat{\sigma}$ cross. Seeds were collected, plated, and stratified as described above. After $7 \mathrm{~d}$ seedlings were transferred to soil, and $7 \mathrm{~d}$ later leaves were collected for DNA extraction and genotyping using primers indicated in Table S1. Numbers relative to Atbop1-2 wild-type:heterozygous segregation were obtained at F1.

\subsection{Arabidopsis phenotypical analyses}

Phenotypic analyses were performed on plants in the F3 generation. At early stages of development approximately 50 seeds per genotype were plated as described on MS media and phenotypes assessed 5 and $12 \mathrm{~d}$ after transfer to light. For root elongation assays seeds were plated and stratified in vertical plates before being transferred to light. After $4 \mathrm{~d}$ under light 20 to 25 seedlings were transferred to new vertical plates and root length was scored every day for 1 week. Roots were then imaged on a flat-bed scanner, and total length and daily elongation were measured using Image Tool 3.0. For hypocotyl elongation assays approximately 30 seeds per genotype per repetition were plated on vertical plates and incubated 4 days in darkness after stratification. Seedlings were imaged using Image Tool 3.0. All assays were conducted three times with three independent seed batches.

\subsection{Protoplast isolation and flow cytometry analysis}

Three-week-old Arabidopsis seedlings were grown as described above. Whole seedlings ( 0.5 to $1 \mathrm{~g}$ ) were collected, placed in a petri dish with $12 \mathrm{ml}$ of a $1.5 \%$ cellulase, $0.4 \%$ macerozyme solution $(0.4 \mathrm{M}$ mannitol, $20 \mathrm{mM} \mathrm{MES} \mathrm{pH} \mathrm{5.7,} 20 \mathrm{mM} \mathrm{KCl}, 10 \mathrm{mM} \mathrm{CaCl}_{2}$ ), cut with a razor blade, and incubated overnight under darkness. The next day a slight rotation of the petri dish helped protoplast release. The solution was passed through a $100 \mathrm{~m}$ filter into a $50 \mathrm{ml}$ tube using a transfer pipet, spun down for $5 \mathrm{~min}$ at $100 \mathrm{~g}$ and the supernatant discarded. The protoplasts were washed twice with $10 \mathrm{ml}$ of a W5 solution (154 $\mathrm{mM} \mathrm{NaCl}, 5 \mathrm{mM} \mathrm{KCl}, 125 \mathrm{mM} \mathrm{CaCl} 2,2 \mathrm{mM} \mathrm{MES} \mathrm{pH} \mathrm{5.7),} \mathrm{and} \mathrm{a} \mathrm{final} \mathrm{volume} \mathrm{of} \mathrm{W5} \mathrm{was} \mathrm{used} \mathrm{to} \mathrm{obtain} \mathrm{a}$ protoplast concentration of $1 \times 10^{6}$ cells $\mathrm{ml}^{-1}$. Two $\mathrm{ml}$ of this solution was divided in 4 aliquots for flow cytometry analysis in each repetition and for each genotype. Following a previously described protocol [36], the protoplasts were spun down and resuspended in a homogenization buffer $(45 \mathrm{mM} \mathrm{MgCl}, 20$ 
mM MOPS, $30 \mathrm{mM}$ sodium citrate, $0.1 \%(\mathrm{v} / \mathrm{v})$ Triton $\mathrm{X}-100, \mathrm{pH}$ adjusted to 7.0 with $\mathrm{NaOH}$, filtered through a $0.22 \mathrm{~m}$ filter), and passed sequentially through a $50 \mathrm{~m}$ and a $20 \mathrm{~m}$ filter (Partec). $1 \mathrm{mg} \mathrm{ml}^{-1}$ of propidium iodide was then added to each sample to a final concentration of $200 \mathrm{~g} \mathrm{ml}^{-1}$, and $1 \mathrm{mg} \mathrm{ml}^{-1}$ of RNase to a final concentration of $10 \mathrm{~g} \mathrm{ml}^{-1}$. The samples were incubated 5 minutes on ice prior flow cytometry analysis on an Accuri C6 (BD-Biosciences) flow cytometer. This instrument uses a laser emitting at $488 \mathrm{~nm}$ to excite propidium iodide and generate forward and side light scatter signals on each particle. Fluorescent emission was collected in the range of $585+/-20 \mathrm{~nm}$. Data for 30,000 particles was recorded for each sample. The resulting data files were analyzed using FCS Express 4 software (Denovo Software). Density plots were created for side light scatter vs propidium iodide fluorescence, and for forward light scatter vs propidium iodide fluorescence. Log scales were used for the density plots. Gates were drawn on each plot to exclude obvious debris particles and clumps, both of which had greater light scatter than free nuclei. Then a Multicycle histogram was created, which provided the best fit to the cell cycle (G1, S, and G2/M) fractions. A linear $\mathrm{x}$-axis scale was used at this point and focused to clearly visualize the cell cycle distribution and graphically evaluate the fit. Flow cytometry on strawberry tissues was performed as described [37]. 


\section{Results}

\subsection{FvBOP1 is conserved within eukaryotes}

The full-length cDNA of FVBOP1 was amplified from the diploid strawberry ( $F$. vesca, Hawaii-4). Sequence analysis reveals 17 predicted exons. The encoded protein is composed of 751 amino acids with an expected $\mathrm{N}$-terminal BOP1 domain and $6 \mathrm{C}$-terminal WD repeats (Fig. 1A). Phylogenetic clustering of BOP1 from strawberry and diverse species depicts conserved motifs within this protein (Fig. 1B). Strawberry BOP1, FvBOP1, is represented in GenBank with the accession number KR092314.

\subsection{FvBOP1 transcript accumulates in different tissues}

FVBOP1 transcripts were detected in all the strawberry tissues examined, including runner tips, leaves at different stages of development, flowers, fruits and roots (Fig. 2). Quantification by real-time PCR showed FVBOP1 transcripts to be more abundant in emerging leaves and runner tip tissues than in mature leaves and roots (Fig. 2).

\subsection{FvBOP1 shows subnuclear localization}

FvBOP1 was fused to GFP in transient expression vectors and then infiltrated into Nicotiana benthamiana leaves to test subcellular localization. A vector expressing only GFP was used as a negative control for localization (not shown). GFP fusions with sequences encoding the maize URP splicing factor, known to localize to the nucleolus, and $U_{2 A F^{65}} \mathrm{a}$, which localizes to the nucleoplasm, were used as positive controls [23]. The results indicate that FvBOP1 accumulation is enriched in subnuclear bodies, consistent with its localization to the nucleolus as observed in other organisms (Fig. 3).

\subsection{Suppression of FvBOP1 by RNAi results in pleiotropic defects}

RNAi-mediated transcript suppression was used to generate FvBOP1-impaired plants. The vector contained two head-to-head copies of the $3^{\prime}$ region of FVBOP1 CDNA under control of the CaMV $35 \mathrm{~S}$ promoter and the plasmid was transformed into F. vesca Hawaii-4. More than 20 independent T0 transgenic lines were analyzed. The plants exhibited pleiotropic defects throughout development. The bop1 silencing lines generally possessed larger and darker leaves than the wild-type (Fig. 4B), and larger flowers (Fig. 4C). These symptoms were consistent with the plants being polyploid, but flow cytometry revealed that leaf samples were identical to diploid controls (not shown). 
Three lines with decreased FVBOP1 transcript accumulation were selected for further analysis (Fig. 4A). Some leaves of the Fvbop1 RNAi lines differ from the wild-type trifoliate pattern, instead displaying an abnormal leaflet separation or presenting a cup-shaped appearance (Fig. 4B). Aberrant morphology was also observed in the development of runners. Fvbop1 RNAi lines did not show the typical arrangement of two pairs of trifoliate leaves observed in the wild-type (Fig. 4D). Decreased FVBOP1 expression results in an increase in anthocyanin levels in leaves and petioles compared to nontransgenic plants, with 2-6 fold anthocyanin increases in leaves and 6-10 fold increases in petioles (Fig. 4E). The Fvbop1 RNAi plants did not produce fruits, and all lines senesced and died rapidly after setting several flowers and runners. The runners were used for plant propagation and subsequent analysis.

\subsection{Evidence of rRNA processing defects}

Based on the knowledge that BOP1 has a role in rRNA processing and ribosome biogenesis, rRNA profiles were examined in the Fvbop1 lines and non-transformed controls using RNA-gel-blot hybridization. The FVBOP1 suppressed lines exhibited accumulation of atypical rRNA intermediates that are not detected in non-transgenic controls, with lines 1 and 4 presenting higher steady-state levels of the defective splicing variant (Fig. 5). The same products were observed in line 2 upon slight overexposure (Supplementary Figure S1).

\subsection{Characterization of $A t B O P 1$ and isolation of T-DNA insertion lines}

The Arabidopsis BOP1 ortholog (At2g40360) has 14 exons and encodes a predicted protein with 753 amino acids that possesses both the $\mathrm{N}$-terminal BOP1 domain and 6 WD repeats at the C-terminal (Fig. $6 \mathrm{~A})$, as described previously [20]. To study the in vivo function of AtBOP1, four T-DNA insertion lines (named Atbop1-1 - Atbop1-4) were identified and characterized (Fig. 5A). Atbop1-1 (SALK_016470) contains a T-DNA insertion in the likely 5'UTR, 57 bp upstream of the predicted start codon, Atbop1-2 (GK_669H09) contains a T-DNA insertion in intron 3 (743 bp downstream of the predicted start codon), the T-DNA in Atbop1-3 (SALK_084687) is located in the promoter region (277 bp upstream of the predicted start codon), and Atbop1-4 (SALK_075405C) was predicted to have an insertion in exon 2 (354 bp downstream of the start codon) (Fig. 6A). Homozygous lines were isolated for Atbop1-1 and Atbop1-3 (Fig. 6B). It was not possible to isolate a homozygous line from Atbop1-2 (Fig. 6B). Of the 79 seedlings genotyped from the heterozygous Atbop1-2 self cross, $69 \%$ of seedlings in the next generation had no TDNA insertion and $31 \%$ were heterozygous. It was also not possible to locate a T-DNA insertion in Atbop1-4 between the $5^{\prime}$ and $3^{\prime}$ UTRs of AtBOP1. In Atbop1-1 the transcript was 50\% lower than in 
comparable wild type seedlings (Fig. 6C), while the T-DNA insertion into Atbop1-3 does not substantially alter AtBOP1 expression (Fig. 6C).

\subsection{A mutation in AtBOP1 affects gametogenesis}

The inability to isolate a homozygous Atbop1-2 line suggested that the condition is lethal and/or gametogenesis is impaired. Siliques from mature Atbop1-2 heterozygous plants were examined, and displayed undeveloped ovules, which result in open spaces within the silique (Fig. 7A). To assess the transmission efficiency of the Atbop1-2 allele, we performed reciprocal crosses between Atbop1-2 and wild-type plants. Genotyping progeny from a WT $\hat{\delta}(+/+)$ x Atbop1-2 $q(+/-)$ revealed 100\% wild-type and $0 \%$ heterozygous seedlings (Table 1). The reciprocal cross from Atbop1-2 $\delta(+/-) \times$ WT $\circ(+/+)$ resulted in $78 \%$ wild-type and $22 \%$ heterozygous seedlings (Table 1). If Atbop1-2 male gametes were fully viable a ratio of 1:1 wild-type to heterozygous were expected. These results show that Atbop1-2 mutant allele transmission does not occur through female gametes and is reduced through male gametes. Undeveloped ovules were also observed in homozygous Atbop1-1 plants (Fig. 7A). These siliques also likely contained aborted embryos, as inferred from brown wrinkled seeds (Fig. 7A).

\subsection{Downregulation of $A t B O P 1$ expression affects cell division}

Due to the inability to isolate a viable homozygous Atbop1-2 line, the transcript-accumulation impaired allele AtBOP1-1 was used for phenotypical analyses. Atbop1-1 plants displayed aberrant phenotypes throughout development, including differences in early seedling development (Fig. 7B). These included failure to produce two cotyledons (approximately 15\% of the Atbop1-1 population), the formation of three cotyledons (20\%), the display of two cotyledons with asymmetrical shapes (7\%), or the emergence of two seedlings from a single a seed coat (3.5\%). After two weeks these phenotypes become less distinct, but Atbop1-1 seedlings still displayed more elongated leaves (Fig. 7B). At this age Atbop1-1 plants have roots with about half the length of the wild-type (Fig. 7C). Root elongation assays performed for one week at this stage of development revealed differences in elongation rates between both genotypes. In the first five days the wild-type presented higher daily root elongation rates than Atbop11. After day 5 this difference disappeared (Fig. 7C). When grown in darkness, Atbop1-1 also showed shorter hypocotyls relative to wild-type, resulting in a length about $60 \%$ of the Col-0 length after $96 \mathrm{~h}$ (Fig. 7D).

These observations, combined with the known role of BOP1 in controlling cell division [2] led to the hypothesis that Atbop1-1 was impaired in cell cycle progression. To test this hypothesis, protoplasts 
were isolated from three week-old Atbop1-1 and wild-type seedlings, and then analyzed by flow cytometry. A shift in the number of polyploid cells was detected in Atbop1-1 mutants when compared to Col-O (Fig. 7E). Quantification of these observations revealed some discrepancies in the relative percentages of $\mathrm{G} 1, \mathrm{~S}$ and $\mathrm{G} 2$ contributions between independent experiments. However, in each repetition Atbop1-1 showed lower relative contributions of cells in G1 and higher in G2 than the wildtype. 


\section{Discussion}

The production of ribosomes is a prerequisite for cell division, requiring coordinated action of many proteins to guide their proper assembly. The BOP1 protein is essential in this process in yeast and animal cells, with a role in ribosomal RNA processing, and by extension ribosome biogenesis. There is limited information on BOP1 in plants, but its role in ribosome biogenesis has been suggested [20]. In this study we describe the roles of BOP1 in planta, by describing the effects of diminished transcript accumulation in two species, the diploid strawberry and Arabidopsis thaliana. Both plant species possess a single gene encoding a protein containing the BOP1 domain and 6 WD repeats. BOP1-transcript compromised strawberry plants exhibit defects in pre-rRNA processing, along with morphological differences. Examination of T-DNA insertion lines in Arabidopsis provides evidence that normal BOP1 transcript levels are essential for plant viability and decreased BOP1 transcript levels result in developmental abnormalities that are likely tied to atypical cell division.

Consistent with the role of AtBOP1 in ribosome biogenesis [20], the findings show accumulation of atypical rRNA splicing intermediates in strawberry bop1 RNAi lines. RNA-gel-blot experiments showed the presence of extra RNA products, likely arising from 18S rRNA, as the extra bands hybridized to an 18S-specific probe. Similar analyses in Arabidopsis did not detect aberrant rRNA variants. There is evidence of incorrect rRNA processing in heterozygous T-DNA insertion mutations in ribosome biogenesis-related genes [38]. The observations from strawberry are consistent with those in mammals and yeast, where altered expression of ribosome biogenesis-related factors, including BOP1, results in the accumulation of aberrant forms of rRNA molecules $[4,9,10]$. The subnuclear localization of FvBOP1 is consistent with its partitioning to the nucleolus, and a likely role in rRNA processing.

The observations in BOP1 transcript-deficient lines in two plant species extend what is known from other eukaryotes to plants, building on the data obtained from tobacco cultures. Preliminary experiments attempted to complement the yeast Erb1p mutant with FvBOP1 but did not generate transformants, so results were inconclusive. Mammalian BOP1 was not viable when transformed into the yeast mutant [10], suggesting that while BOP1 has conserved functions across eukaryotes, the mechanism of action may rely on integration with species-specific factors. Complementation may also be precluded by high constitutive expression of this essential protein, as it has been proposed that cells tightly regulate BOP1 levels through series of feedback mechanisms that guarantee appropriate steadystate levels of the protein [18].

The results indicate that normal BOP1 transcript levels are required for normal growth and development. Low transcript levels or null mutations are lethal. Similarly BOP1 is essential in yeast and 
necessary for cell cycle progression in mammals $[2,10]$. The Atbop1-2 allele is not transmitted through female gametes and has low rate of transmission through male gametes. This T-DNA line has an insertion within the coding region. T-DNA insertions within coding sequences tend to affect normal gene expression [39]. An Atbop1-2 homozygous line would likely be a BOP1 true null mutant. The rate of transmission of Atbop1-2 together with the sterility of RNAi strawberry lines indicate BOP1 is necessary for proper gametophyte development in plants. Other factors related to rRNA processing have similar roles. The swa1 mutant, which exhibits low levels of the $18 \mathrm{~S}$ pre-rRNA processing factor SLOW WALKER 1 , is semisterile. It was first identified in a screen for gametophytic mutants with distorted Mendelian segregation in Arabidopsis [40]. A null allele in NOF1, encoding a protein involved in rRNA expression, is not transmitted through female gametes and has reduced transmission through pollen [41]. Another report examined five additional co-factors (RRP5, PWP2, NOB1, ENP1, and NOC4) related to the maturation of the $40 \mathrm{~S}$ ribosome subunit in Arabidopsis and found them to be essential for gametophyte development, and the mutants show different rates of transmission through the male or female gametophytes [38]. The ribosomal protein RPL27 also promotes female gametophyte development [42], similar to the ribosomal biogenesis factors MDN1 and NLE [43].

FVBOP1 is expressed at higher levels in younger and presumably actively-dividing tissues. Strawberry and Arabidopsis transcript-impaired lines display similar abnormalities, such as aberrant leaf shape and number. Root length and elongation rates were also affected in Atbop1-1. Stable strawberry transgenic lines with reduced BOP1 transcripts exhibited many symptoms consistent with polyploidy [44]. Reduced BOP1 expression led to increased anthocyanin levels, which can be an indication of overall stress [45]. The RNAi lines also consistently presented larger flowers, atypically-shaped leaves and unusual runners. These phenotypes were consistent with polyploid plants, yet the materials assayed appeared as diploid by flow cytometry, at least there was not a conspicuous shift to polyploid cell numbers. It was revealed by analyses in Arabidopsis that Arabidopsis bop1-1 mutants do in fact possess a greater number of polyploid cells. Transient depletion of Bop1 in a human cell culture has been shown to increase the number of abnormal mitoses with appearance of binucleate or hyperploid cells, or cells with multipolar spindles and of aberrant metaphases plates [13]. Another report described the inhibition of cell proliferation by BOP1 overexpression in mammalian cells [18]. Loss-of-function of the Arabidopsis ribosome biogenesis factor LSG1-2 similarly results in the occurrence of three cotyledons or two but fused together [46]. The ribosomal-related proteins OLI2/5/7 and ERB1 have been implicated in control of the cell cycle, cell proliferation and organ size determination in plants $[47,48]$. Abnormal leaf shape has also been observed by disruption of Arabidopsis CUP-SHAPED COTYLEDON (CUC) genes, and 
of Antirrhinum majus CUPULIFORMIS, which play roles in shoot organ boundary and meristem formation $[49,50]$. Future studies may assess if BOP1 is related to meristem activity.

Other factors involved in rRNA processing have been linked to ensure correct progression into the cell cycle in plants. SWA1 depletion affects mitosis in the female gametophyte and processing of the 18S pre-rRNA [40]. SWA2, homologous to yeast Mak21p, which is involved in ribosome biogenesis, and NOF1 are equally associated with the regulation of cell cycle control during female gametogenesis [41, $51]$.

In strawberry, the vigor of bop1 RNAi lines declined rapidly upon flowering, with plants senescing rapidly upon return to vegetative growth suggesting that a new set of ribosomes may be needed for the return to the perennial, vegetative program. The Arabidopsis loss-of-function line Atbop1-1 was able to produce seeds. It is possible that this difference between the two plant species results from a lower reduced BOP1 activity in Atbop1-1 relative to strawberry silenced lines. Alternatively, BOP1 may be particularly relevant in perennial plants during the switch from flowering to vegetative growth. Future studies will address the molecular mechanisms at the basis of this phenomenon.

Some differences of BOP1 activity have been reported by comparing studies in mammals and yeast. While depletion of the protein activity causes cell cycle arrest in mouse, yeast cells become unviable [10]. Multiple effects result from different BOP1 mutants [1], and the integrity of the PeBoW complex depends on a coordinated regulation of each of its members level [18, 52]. BOP1 promotes cell differentiation in humans. Reduced BOP1 transcript levels inhibit the transition of epithelial to mesenchymal cells, a process implicated in cancer progression and metastases, independently of its role related to ribosomal biogenesis [14]. This transition requires cells to undergo changes associated with cytoskeleton reorganization and loss of cell-cell adhesion structures and polarity [53].

Because BOP1 structure and role in ribosome biogenesis are conserved throughout eukaryotes, it is likely that organism-specific roles require species-specific factors, perhaps even tuned to function in discrete developmental transitions. This hypothesis is consistent with the role of BOP1's requirement for a return to vegetative growth after flowering. Similarly, the WD40 repeat protein Gigantus 1 (GTS1) physically interacts with two ribosomal proteins (Nop16 and L19e) and controls seed germination, growth rates and biomass yield in Arabidopsis [54]. GTS1 is also mainly expressed in the meristem [54]. A study on tobacco ribosomal proteins L3 (RPL3a and RPL3b) revealed their expression to be tightly coordinated and interdependent, controlling leaf size and shape, besides their role in ribosome biogenesis [55]. Other rRNA processing-related factors with roles in embryogenesis show different 
expression patterns, suggesting unique roles during other stages of plant growth [38]. The ribosomal protein RPL27a plays role in meristem activity and organ development [56]. The Arabidopsis protein arginine methyltransferase 3 , whose role could be typically linked to DNA transcription or mRNA splicing, has also been found to regulate ribosome biogenesis [57].

The results of this work expand what is known about this conserved protein in plants. Plants with decreased transcript accumulation show variations in morphology and development that are consistent with a role of the BOP1 protein in rRNA processing, leading to alterations in cell division that affect many aspects of growth and development. Characterization of the BOP1 protein's function in plants is limited by the inability to obtain a null mutant. Future analyses using regulated promoters in a transgenic background, along with interaction studies, may more firmly tie this conserved protein to precise functions in plant cells. 


\section{Conclusions}

Eukaryotes share many commonalities in cell-cycle mechanisms and organellar assembly. The BOP1 protein is conserved among mammals, yeast, and plants. The present report utilizes a transgenic approach in two species to reduce BOP1 transcript accumulation. The resulting plants were characterized for phenotypes. RNAi strawberry lines exhibited defects in rRNA processing, and abnormal cell proliferation was observed in Arabidopsis. Complete loss of BOP1 appears to be lethal. Strawberry RNAi lines and reduced-expression Arabidopsis T-DNA insertion mutants give rise to misshapen leaves, impaired gametogenesis, and other morphological defects, with strawberry RNAi lines senescing rapidly after flowering. This report demonstrates that the BOP1 protein has a role in plants that is consistent with its function in animals and fungi, serving to aid in rRNA processing required for normal cell division and differentiation. 


\section{Acknowledgments}

We thank Neal Benson for support in flow cytometry experiments and analysis, and Dr. Federico Martin for assistance in imaging nucleolar localization. This work was performed with support from the National Science Foundation (IOS-0701488). 
Figure Legends

Fig. 1. Characterization of FvBOP1. A: Genomic structure of FVBOP1, with indication of exons and introns, and predicted domains in FvBOP1; B: neighbor-joining tree between different species where BOP1 has been identified. Bootstrap values based on 1000 replicates are shown next to the branching points.

Fig. 2. FvBOP1 tissue-specific expression. Analysis of FvBOP1 expression by quantitative real-time PCR using levels measured in flowers as reference. Error bars represent standard error of the mean $(n=3)$.

Fig. 3. FvBOP1 subcellular localization to the nucleus. Transient expression in $N$. benthamiana leaves of GFP fused with A: FvBOP1, B: URP, and C: $U 2 A F^{65}$ a.

Fig. 4. Phenotypes observed in plants with repressed FvBOP1 transcript accumulation. A: Analysis by Northern blot of FvBOP1 expression in wild-type (WT) strawberry and 3 RNAi lines (Fvbop1-1, -2 and -4), with total RNA shown as loading control; representative pictures of the WT and Fvbop1 lines of B: leaves, C: flowers (red scale bar $=5 \mathrm{~mm}$ ), and D: runners; E: relative anthocyanin levels in leaves and petioles in WT and Fvbop1 lines.

Fig. 5. rRNA profile in Fvbop1 RNAi lines. RNA-gel-blot analysis on total RNA from WT and Fvbop1 lines using an 18s rDNA probe. The $18 \mathrm{~S}$ and $25 \mathrm{~S}$ rRNA products are noted, and the incorrect products are depicted with the arrow.

Fig. 6. Characterization of AtBOP1 and isolation of T-DNA insertion lines. A: Genomic structure of AtBOP1, with indication of exons and introns; indication of the T-DNA insertion sites and the locations of the primers used for genotyping; B: Genotyping results for the 4 T-DNA lines, letters and numbers correspond to the primers in panel A; C: analysis of BOP1 expression levels by quantitative real-time in the 2 homozygous lines; error bars represent standard errors of means $(n=3)$. 
Fig. 7. Phenotypes derived from lowered AtBOP1 expression. Representative pictures of A: wild-type (Col-0), Atbop1-1 and Atbop1-2 dissected siliques and B: 5 and 12 day-old seedlings of Col-0 and Atbop11 grown under standard conditions; C: representative pictures of 11 day-old whole seedlings of Col-0 and Atbop1-1 and total root length, and daily elongation rates from day 5 to day 11; D: hypocotyl length of 4 day-dark grown Col-0 and Atbop1-1; E: flow cytometry plots obtained from Col-0 and Atbop1-1 protoplasts; plots are representative of three independent experiments. White scale bars $=5 \mathrm{~mm}$. Error bars represent standard error of the mean. Asterisks indicate significantly different values based on a ttest $(p<0.01)$. 


\section{References}

[1] Z. Strezoska, D.G. Pestov, L.F. Lau, Functional inactivation of the mouse nucleolar protein Bop1 inhibits multiple steps in pre-rRNA processing and blocks cell cycle progression, J Biol Chem, 277 (2002) 29617-29625.

[2] D.G. Pestov, Z. Strezoska, L.F. Lau, Evidence of p53-dependent cross-talk between ribosome biogenesis and the cell cycle: effects of nucleolar protein Bop1 on G(1)/S transition, Mol Cell Biol, 21 (2001a) 4246-4255.

[3] D. Kressler, E. Hurt, J. Bassler, Driving ribosome assembly, Biochim Biophys Acta, 1803 (2010) 673683.

[4] D. Kressler, P. Linder, J. de La Cruz, Protein trans-acting factors involved in ribosome biogenesis in Saccharomyces cerevisiae, Mol Cell Biol, 19 (1999) 7897-7912.

[5] A.K. Henras, C. Plisson-Chastang, M.F. O'Donohue, A. Chakraborty, P.E. Gleizes, An overview of preribosomal RNA processing in eukaryotes, Wiley Interdiscip Rev RNA, (2014).

[6] J.W. Brown, P.J. Shaw, The role of the plant nucleolus in pre-mRNA processing, Curr Top Microbiol Immunol, 326 (2008) 291-311.

[7] W. Wang, S. Nag, X. Zhang, M.H. Wang, H. Wang, J. Zhou, R. Zhang, Ribosomal Proteins and Human Diseases: Pathogenesis, Molecular Mechanisms, and Therapeutic Implications, Med Res Rev, (2014).

[8] D.G. Pestov, T.M. Grzeszkiewicz, L.F. Lau, Isolation of growth suppressors from a cDNA expression library, Oncogene, 17 (1998) 3187-3197.

[9] Z. Strezoska, D.G. Pestov, L.F. Lau, Bop1 is a mouse WD40 repeat nucleolar protein involved in 28S and 5. 8S RRNA processing and 60S ribosome biogenesis, Mol Cell Biol, 20 (2000) 5516-5528.

[10] D.G. Pestov, M.G. Stockelman, Z. Strezoska, L.F. Lau, ERB1, the yeast homolog of mammalian Bop1, is an essential gene required for maturation of the $25 S$ and 5.8 S ribosomal RNAs, Nucleic Acids Res, 29 (2001b) 3621-3630.

[11] A. Killian, N. Sarafan-Vasseur, R. Sesboue, F. Le Pessot, F. Blanchard, A. Lamy, M. Laurent, J.M. Flaman, T. Frebourg, Contribution of the BOP1 gene, located on 8q24, to colorectal tumorigenesis, Genes Chromosomes Cancer, 45 (2006) 874-881.

[12] J. Kim, S. Sim, T.S. Yong, S.J. Park, Interaction of BOP1, a protein for ribosome biogenesis, with EB1 in Giardia lamblia, Parasitol Res, 103 (2008) 1459-1464.

[13] A. Killian, N. Le Meur, R. Sesboue, J. Bourguignon, G. Bougeard, J. Gautherot, C. Bastard, T. Frebourg, J.M. Flaman, Inactivation of the RRB1-Pescadillo pathway involved in ribosome biogenesis induces chromosomal instability, Oncogene, 23 (2004) 8597-8602.

[14] K.Y. Chung, I.K. Cheng, A.K. Ching, J.H. Chu, P.B. Lai, N. Wong, Block of proliferation 1 (BOP1) plays an oncogenic role in hepatocellular carcinoma by promoting epithelial-to-mesenchymal transition, Hepatology, 54 (2011) 307-318.

[15] M. Holzel, M. Rohrmoser, M. Schlee, T. Grimm, T. Harasim, A. Malamoussi, A. Gruber-Eber, E. Kremmer, W. Hiddemann, G.W. Bornkamm, D. Eick, Mammalian WDR12 is a novel member of the Pes1Bop1 complex and is required for ribosome biogenesis and cell proliferation, J Cell Biol, 170 (2005) 367378.

[16] T.D. Miles, J. Jakovljevic, E.W. Horsey, P. Harnpicharnchai, L. Tang, J.L. Woolford, Jr., Ytm1, Nop7, and Erb1 form a complex necessary for maturation of yeast 66S preribosomes, Mol Cell Biol, 25 (2005) 10419-10432.

[17] L. Tang, A. Sahasranaman, J. Jakovljevic, E. Schleifman, J.L. Woolford, Jr., Interactions among Ytm1, Erb1, and Nop7 required for assembly of the Nop7-subcomplex in yeast preribosomes, Mol Biol Cell, 19 (2008) 2844-2856. 
[18] M. Rohrmoser, M. Holzel, T. Grimm, A. Malamoussi, T. Harasim, M. Orban, I. Pfisterer, A. GruberEber, E. Kremmer, D. Eick, Interdependence of Pes1, Bop1, and WDR12 controls nucleolar localization and assembly of the PeBoW complex required for maturation of the $60 \mathrm{~S}$ ribosomal subunit, Mol Cell Biol, 27 (2007) 3682-3694.

[19] Y.R. Lapik, C.J. Fernandes, L.F. Lau, D.G. Pestov, Physical and functional interaction between Pes1 and Bop1 in mammalian ribosome biogenesis, Mol Cell, 15 (2004) 17-29.

[20] H.K. Cho, C.S. Ahn, H.S. Lee, J.K. Kim, H.S. Pai, Pescadillo plays an essential role in plant cell growth and survival by modulating ribosome biogenesis, Plant J, 76 (2013) 393-405.

[21] N. Kleinboelting, G. Huep, A. Kloetgen, P. Viehoever, B. Weisshaar, GABI-Kat SimpleSearch: new features of the Arabidopsis thaliana T-DNA mutant database, Nucleic Acids Res, 40 (2012) D1211-1215.

[22] V. Shulaev, D.J. Sargent, R.N. Crowhurst, T.C. Mockler, O. Folkerts, A.L. Delcher, P. Jaiswal, K. Mockaitis, A. Liston, S.P. Mane, The genome of woodland strawberry (Fragaria vesca), Nat Genet, 43 (2011) 109-116.

[23] R. Fouquet, F. Martin, D.S. Fajardo, C.M. Gault, E. Gomez, C.W. Tseung, T. Policht, G. Hueros, A.M. Settles, Maize rough endosperm3 encodes an RNA splicing factor required for endosperm cell differentiation and has a nonautonomous effect on embryo development, in: Plant Cell, United States, 2011, pp. 4280-4297.

[24] N. Saitou, M. Nei, The neighbor-joining method: a new method for reconstructing phylogenetic trees, Mol Biol Evol, 4 (1987) 406-425.

[25] K. Tamura, J. Dudley, M. Nei, S. Kumar, MEGA4: Molecular Evolutionary Genetics Analysis (MEGA) software version 4.0, Mol Biol Evol, 24 (2007) 1596-1599.

[26] J. Felsenstein, Phylogenies and the comparative method, The American Naturalist, 125 (1985) 1-15.

[27] S. Chang, J. Puryear, J. Cairney, A simple and efficient method for isolating RNA from pine trees, Plant Molecular Biology Reporter, 11 (1993) 113-116.

[28] A. Dhingra, D.H. Bies, K.R. Lehner, K.M. Folta, Green light adjusts the plastid transcriptome during early photomorphogenic development, Plant Physiol, 142 (2006) 1256-1266.

[29] M.A. Clancy, H.G. Rosli, S. Chamala, W.B. Barbazuk, P.M. Civello, K.M. Folta, Validation of reference transcripts in strawberry (Fragaria spp.), Mol Genet Genomics, 288 (2013) 671-681.

[30] M. Karimi, D. Inze, A. Depicker, GATEWAY vectors for Agrobacterium-mediated plant transformation, Trends Plant Sci, 7 (2002) 193-195.

[31] T. Oosumi, H.A. Gruszewski, L.A. Blischak, A.J. Baxter, P.A. Wadl, J.L. Shuman, R.E. Veilleux, V. Shulaev, High-efficiency transformation of the diploid strawberry (Fragaria vesca) for functional genomics, Planta, 223 (2006) 1219-1230.

[32] M. Chatterjee, C.L. Bermudez-Lozano, M.A. Clancy, T.M. Davis, K.M. Folta, A strawberry KNOX gene regulates leaf, flower and meristem architecture, PLoS One, 6 (2011) e24752.

[33] J.L. Cenis, Rapid extraction of fungal DNA for PCR amplification, Nucleic Acids Res, 20 (1992) 2380.

[34] K. Edwards, C. Johnstone, C. Thompson, A simple and rapid method for the preparation of plant genomic DNA for PCR analysis, Nucleic Acids Res, 19 (1991) 1349.

[35] S.D. Carvalho, K.M. Folta, Sequential light programs shape kale (Brassica napus) sprout appearance and alter metabolic and nutrient content, Horticulture Research, 1 (2014).

[36] D.W. Galbraith, G.M. Lambert, J. Macas, J. Dolezel, Analysis of nuclear DNA content and ploidy in higher plants, Curr Protoc Cytom, Chapter 7 (2001) Unit 7.6.

[37] A.H. Chambers, H. Pollard, K.M. Folta, Limitations of morphological ploidy estimation methods in Fragaria, Journal of Berry Research, 3 (2013) 135-149.

[38] S. Missbach, B.L. Weis, R. Martin, S. Simm, M.T. Bohnsack, E. Schleiff, 40S ribosome biogenesis cofactors are essential for gametophyte and embryo development, PLoS One, 8 (2013) e54084.

[39] B. Ulker, E. Peiter, D.P. Dixon, C. Moffat, R. Capper, N. Bouche, R. Edwards, D. Sanders, H. Knight, M.R. Knight, Getting the most out of publicly available T-DNA insertion lines, Plant J, 56 (2008) 665-677. 
[40] D.Q. Shi, J. Liu, Y.H. Xiang, D. Ye, V. Sundaresan, W.C. Yang, SLOW WALKER1, essential for gametogenesis in Arabidopsis, encodes a WD40 protein involved in 18S ribosomal RNA biogenesis, Plant Cell, 17 (2005) 2340-2354.

[41] E. Harscoet, B. Dubreucq, J.C. Palauqui, L. Lepiniec, NOF1 encodes an Arabidopsis protein involved in the control of rRNA expression, PLoS One, 5 (2010) e12829.

[42] A. Zsogon, D. Szakonyi, X. Shi, M.E. Byrne, Ribosomal Protein RPL27a Promotes Female Gametophyte Development in a Dose-Dependent Manner, Plant Physiol, 165 (2014) 1133-1143.

[43] S.C. Chantha, M. Gray-Mitsumune, J. Houde, D.P. Matton, The MIDASIN and NOTCHLESS genes are essential for female gametophyte development in Arabidopsis thaliana, Physiol Mol Biol Plants, 16 (2010) 3-18.

[44] Q. Zhang, K.M. Folta, T.M. Davis, Somatic embryogenesis, tetraploidy, and variant leaf morphology in transgenic diploid strawberry (Fragaria vesca subspecies vesca 'Hawaii 4', in review, (2013).

[45] B. Winkel-Shirley, Biosynthesis of flavonoids and effects of stress, Curr Opin Plant Biol, 5 (2002) 218223.

[46] B.L. Weis, S. Missbach, J. Marzi, M.T. Bohnsack, E. Schleiff, The 605 associated ribosome biogenesis factor LSG1-2 is required for 40S maturation in Arabidopsis thaliana, Plant J, (2014).

[47] U. Fujikura, G. Horiguchi, M.R. Ponce, J.L. Micol, H. Tsukaya, Coordination of cell proliferation and cell expansion mediated by ribosome-related processes in the leaves of Arabidopsis thaliana, Plant J, 59 (2009) 499-508.

[48] B.M. Horvath, Z. Magyar, Y. Zhang, A.W. Hamburger, L. Bako, R.G. Visser, C.W. Bachem, L. Bogre, EBP1 regulates organ size through cell growth and proliferation in plants, Embo j, 25 (2006) 4909-4920.

[49] K. Hibara, M.R. Karim, S. Takada, K. Taoka, M. Furutani, M. Aida, M. Tasaka, Arabidopsis CUPSHAPED COTYLEDON3 regulates postembryonic shoot meristem and organ boundary formation, Plant Cell, 18 (2006) 2946-2957.

[50] I. Weir, J. Lu, H. Cook, B. Causier, Z. Schwarz-Sommer, B. Davies, CUPULIFORMIS establishes lateral organ boundaries in Antirrhinum, Development, 131 (2004) 915-922.

[51] N. Li, L. Yuan, N. Liu, D. Shi, X. Li, Z. Tang, J. Liu, V. Sundaresan, W.C. Yang, SLOW WALKER2, a NOC1/MAK21 homologue, is essential for coordinated cell cycle progression during female gametophyte development in Arabidopsis, Plant Physiol, 151 (2009) 1486-1497.

[52] T. Grimm, M. Holzel, M. Rohrmoser, T. Harasim, A. Malamoussi, A. Gruber-Eber, E. Kremmer, D. Eick, Dominant-negative Pes1 mutants inhibit ribosomal RNA processing and cell proliferation via incorporation into the PeBoW-complex, Nucleic Acids Res, 34 (2006) 3030-3043.

[53] H. Son, A. Moon, Epithelial-mesenchymal Transition and Cell Invasion, Toxicol Res, 26 (2010) 245252.

[54] E.W. Gachomo, J.C. Jimenez-Lopez, L.J. Baptiste, S.O. Kotchoni, GIGANTUS1 (GTS1), a member of Transducin/WD40 protein superfamily, controls seed germination, growth and biomass accumulation through ribosome-biogenesis protein interactions in Arabidopsis thaliana, BMC Plant Biol, 14 (2014) 37.

[55] S.C. Popescu, N.E. Tumer, Silencing of ribosomal protein L3 genes in N. tabacum reveals coordinate expression and significant alterations in plant growth, development and ribosome biogenesis, Plant J, 39 (2004) 29-44.

[56] D. Szakonyi, M.E. Byrne, Involvement of ribosomal protein RPL27a in meristem activity and organ development, Plant Signal Behav, 6 (2011) 712-714.

[57] R. Hang, C. Liu, A. Ahmad, Y. Zhang, F. Lu, X. Cao, Arabidopsis protein arginine methyltransferase 3 is required for ribosome biogenesis by affecting precursor ribosomal RNA processing, Proc Natl Acad Sci U S A, 111 (2014) 16190-16195. 
Table 1: Progeny from reciprocal crosses between wild-type (WT) and Atbop1-2.

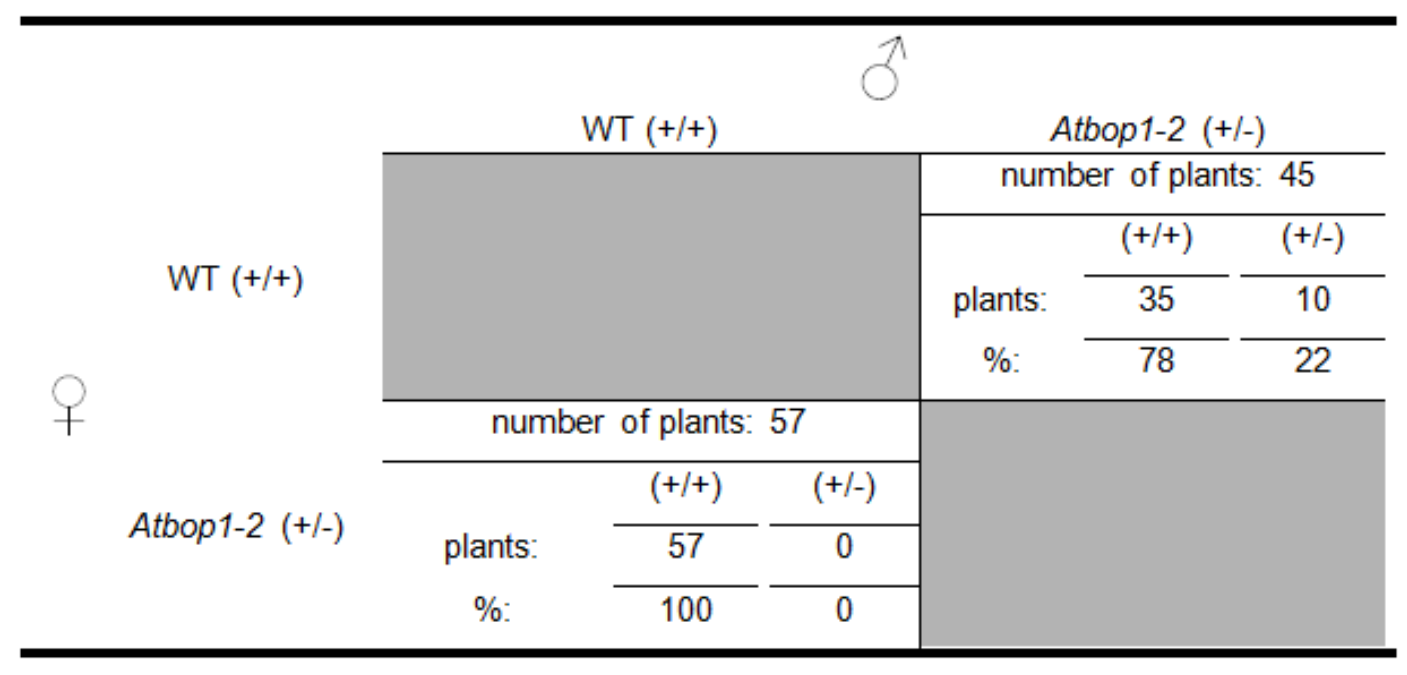


Fig. 1

A

FVBOP1

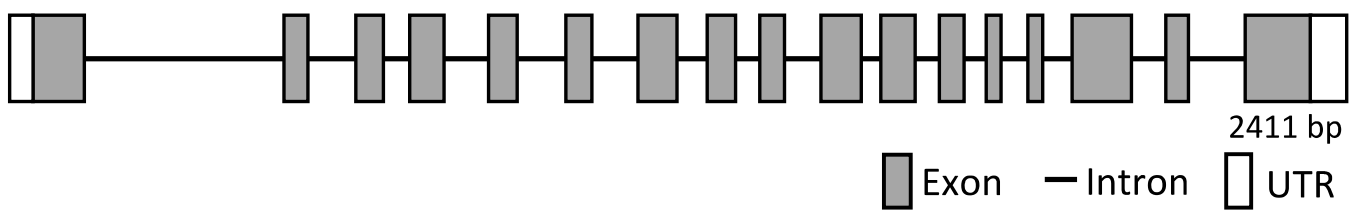

FvBOP1

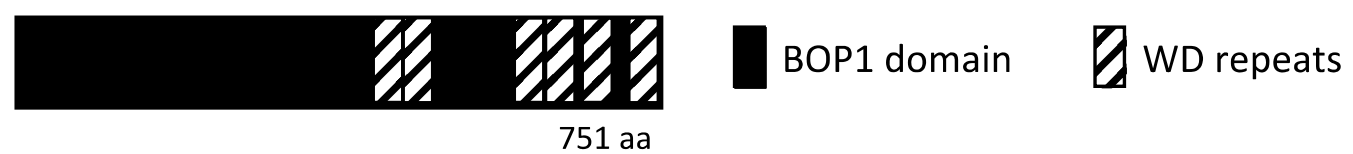

B

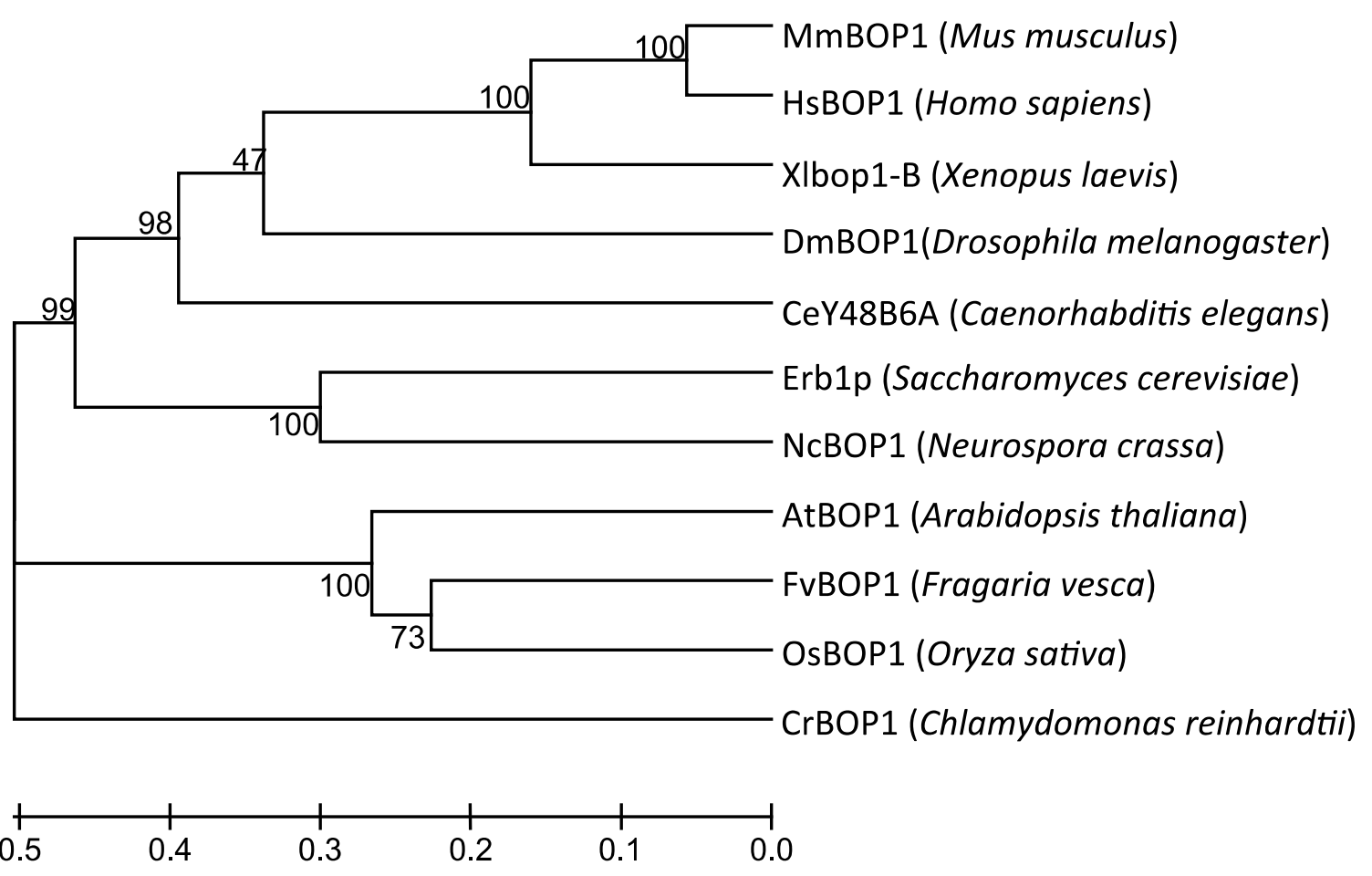


Fig. 2

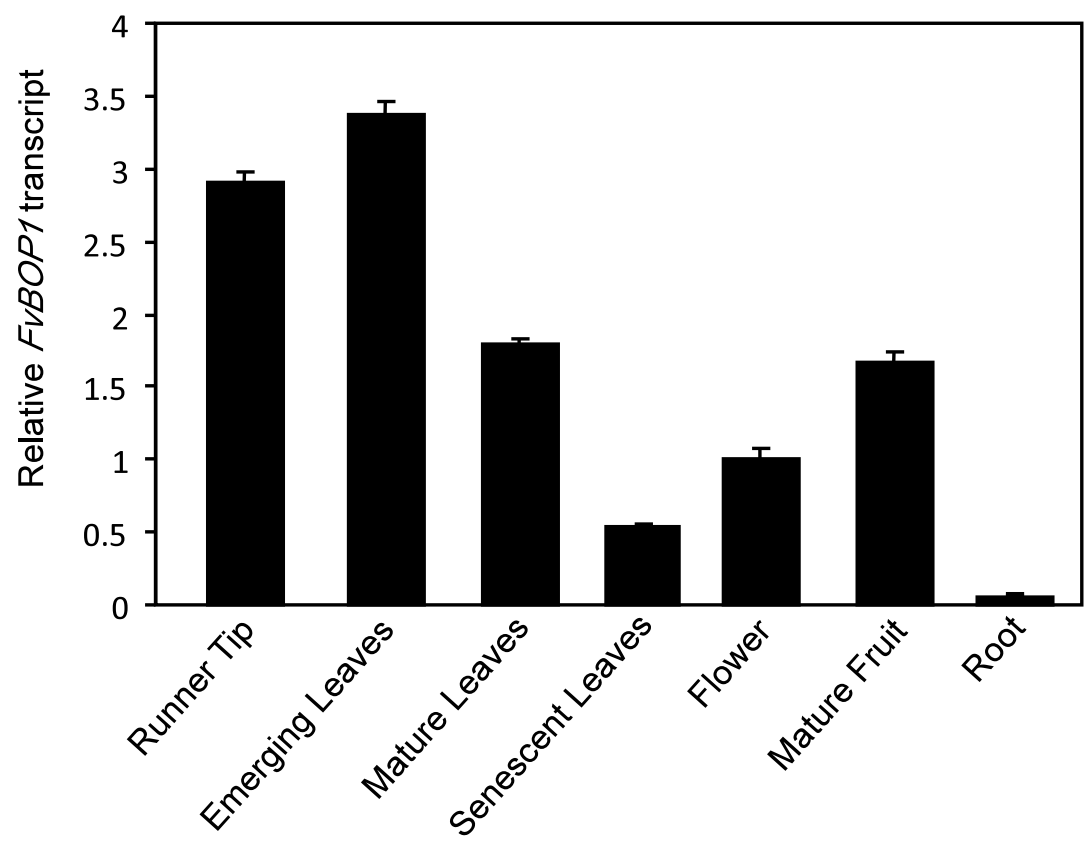


Fig. 3

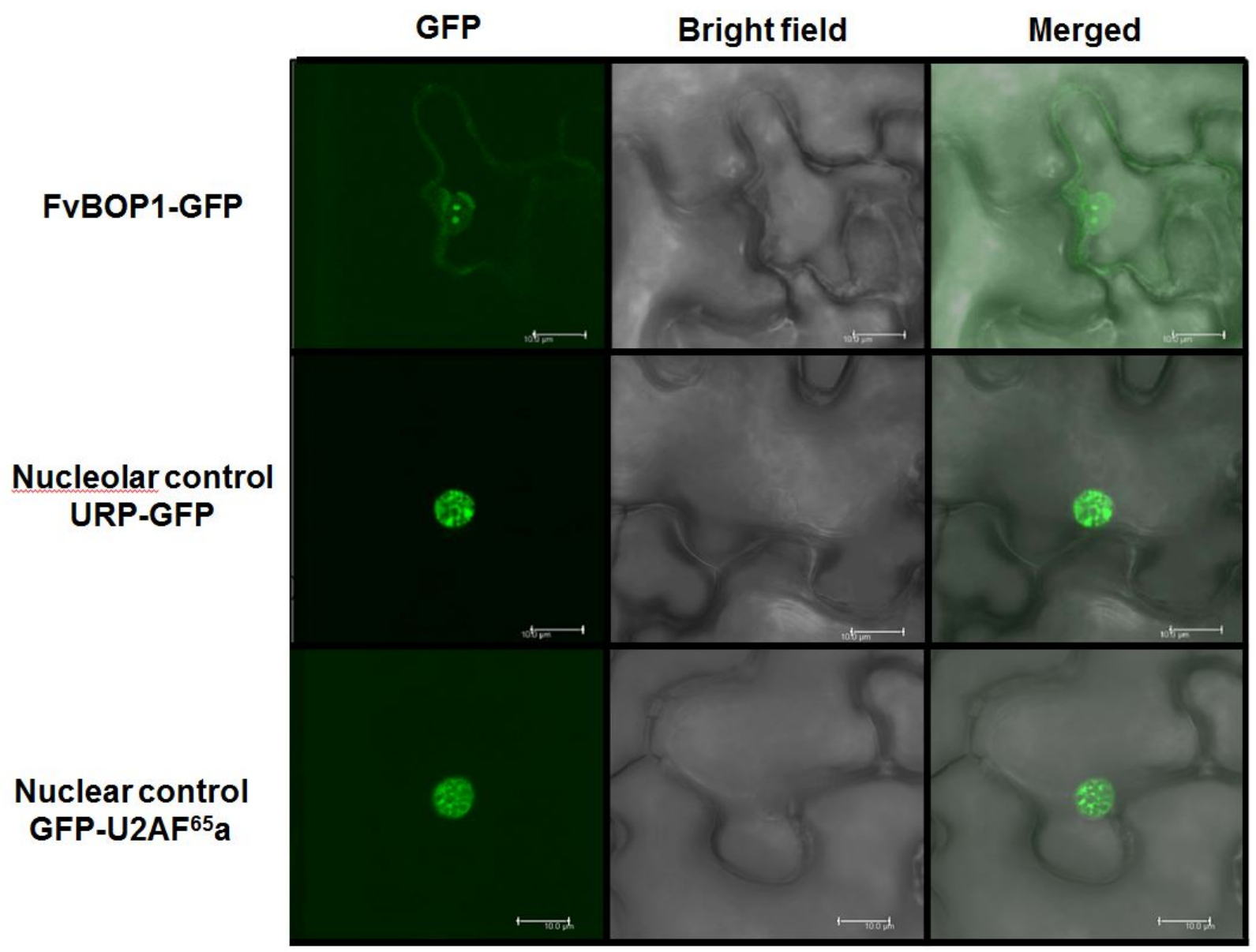


Fig. 4

A

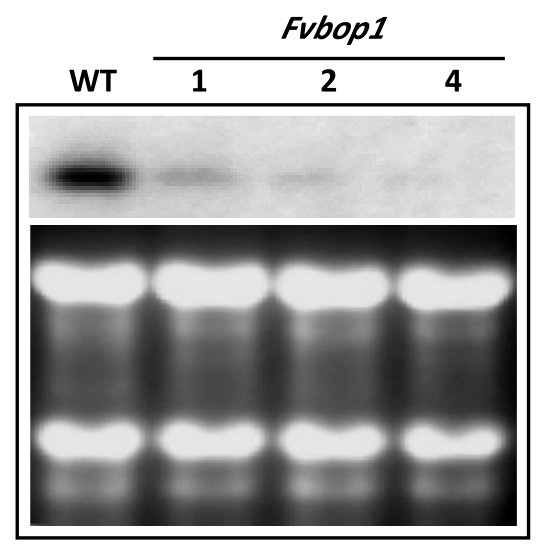

C

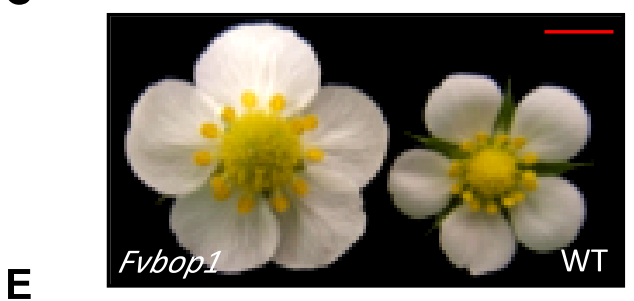

E

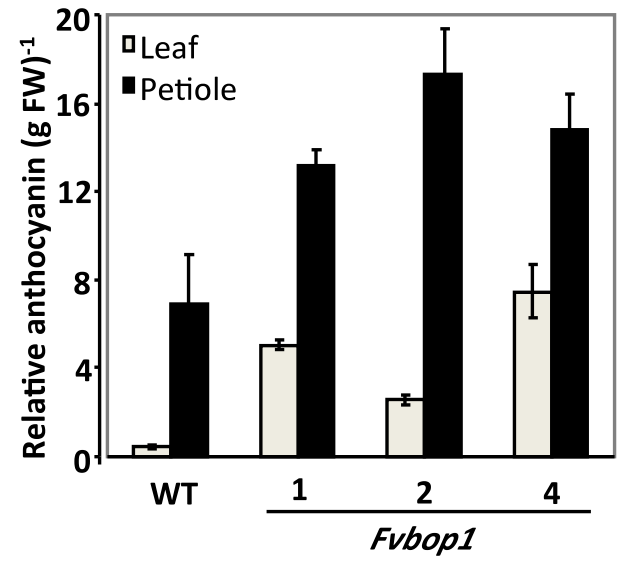

B

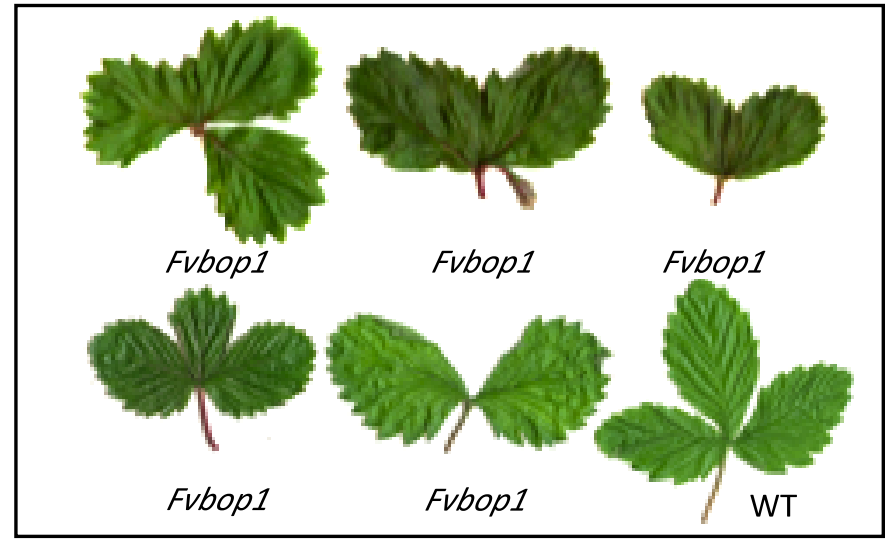

D
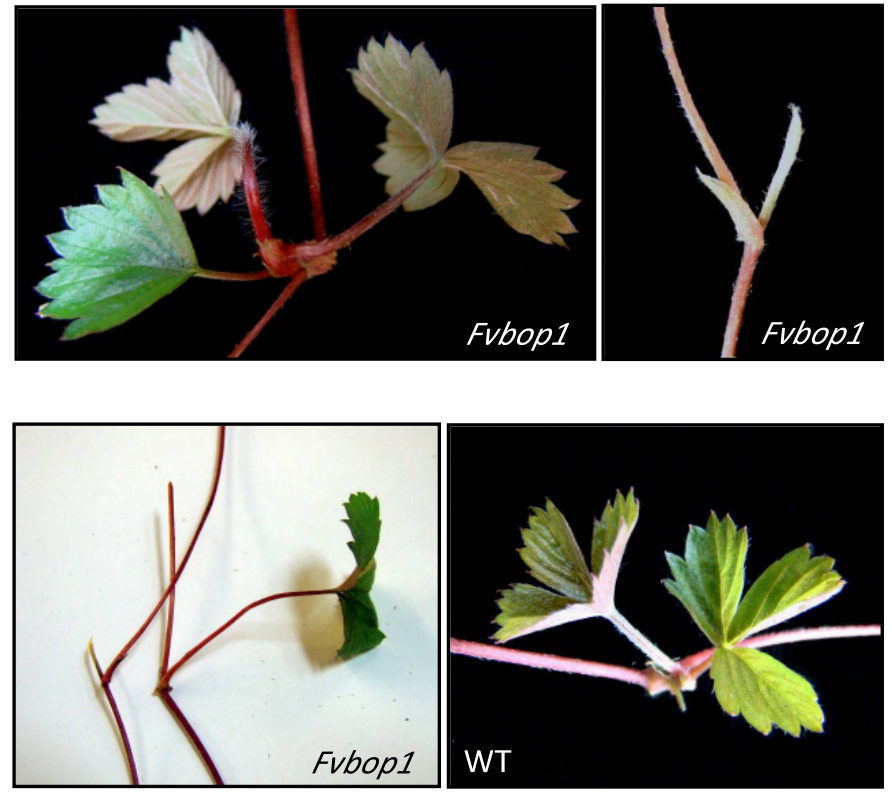
Fig. 5

Fvbop1 RNAi lines

$\begin{array}{llll} & \text { CON } & 1 & 2\end{array}$

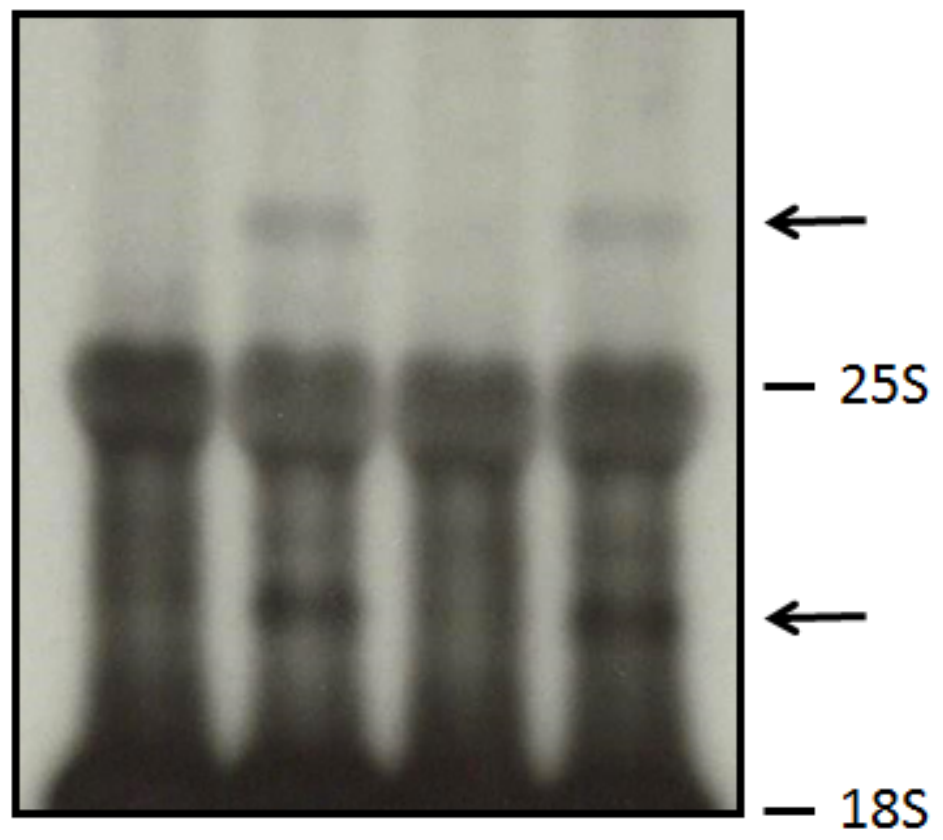


Fig. 6

A

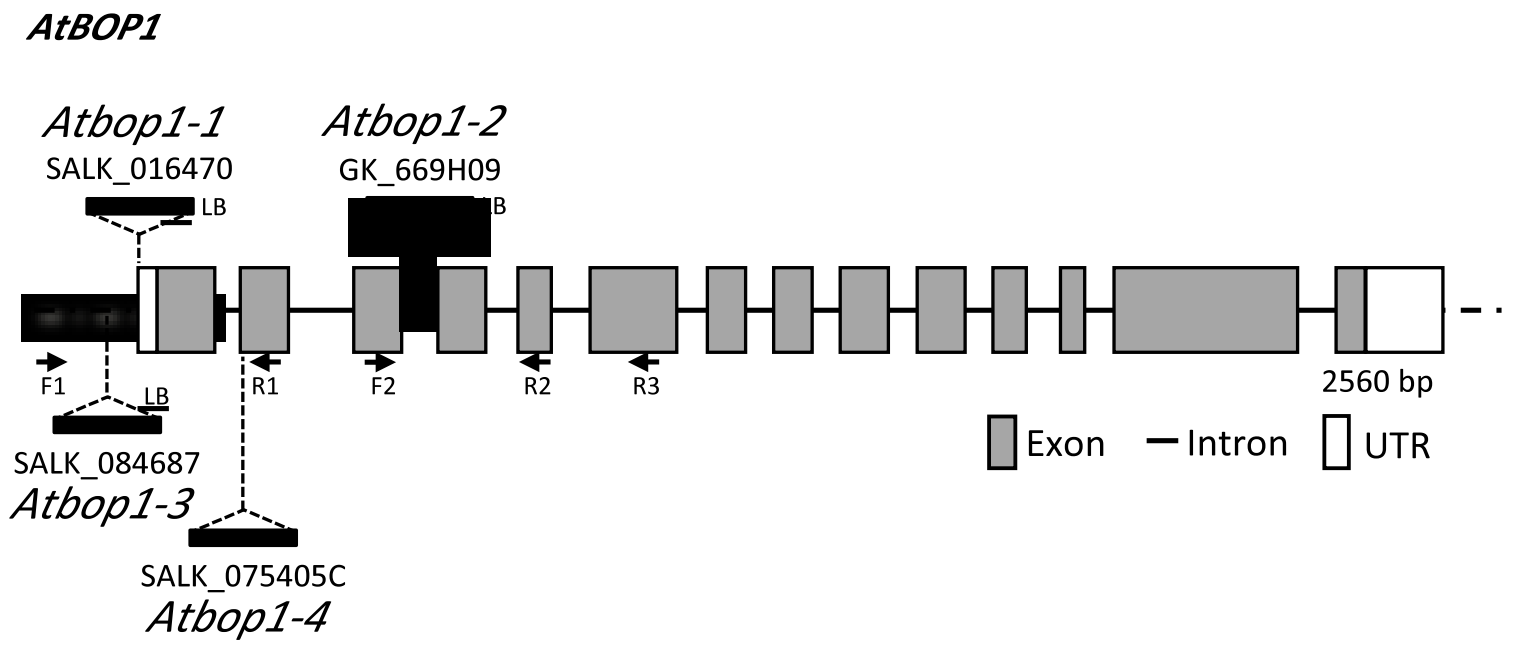

AtBOP1

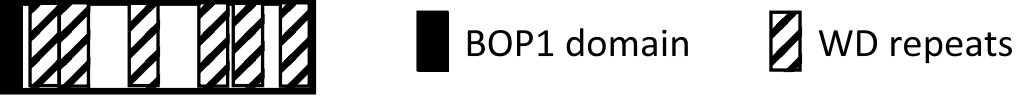

753 aа

B
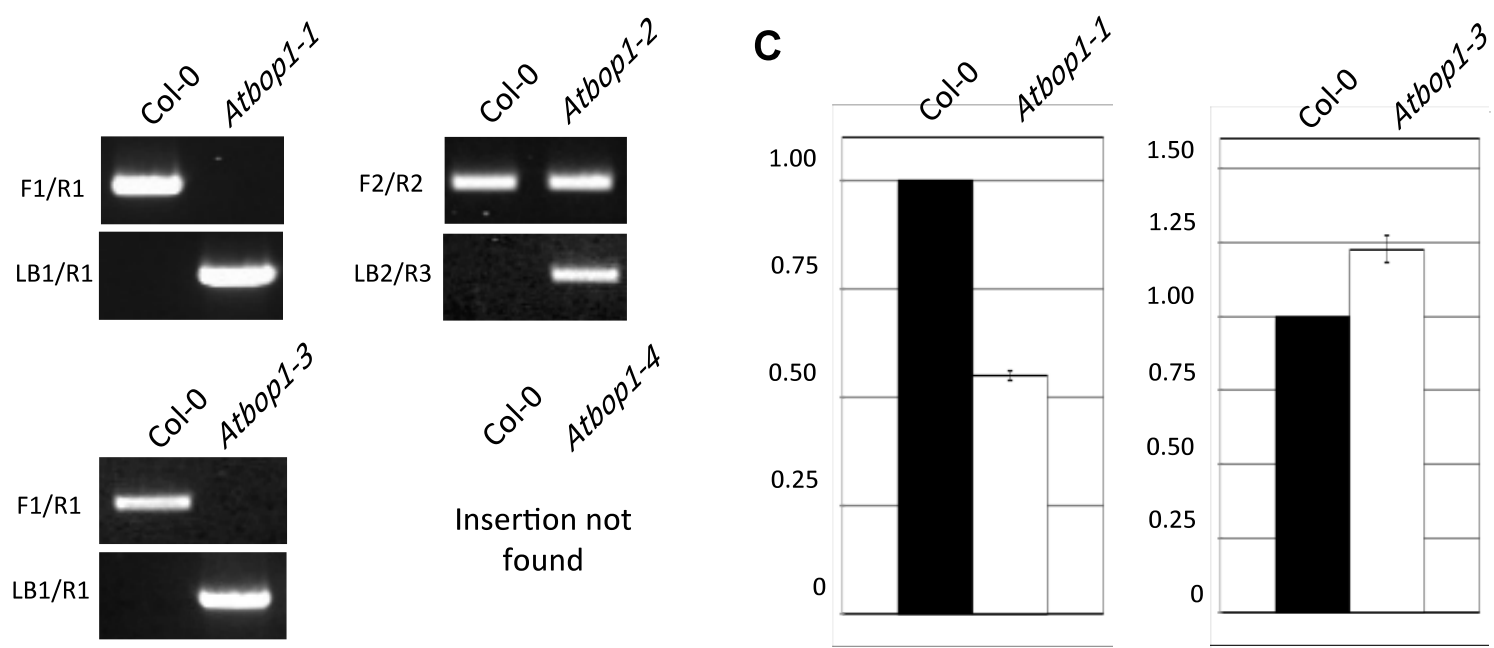
Fig. 7
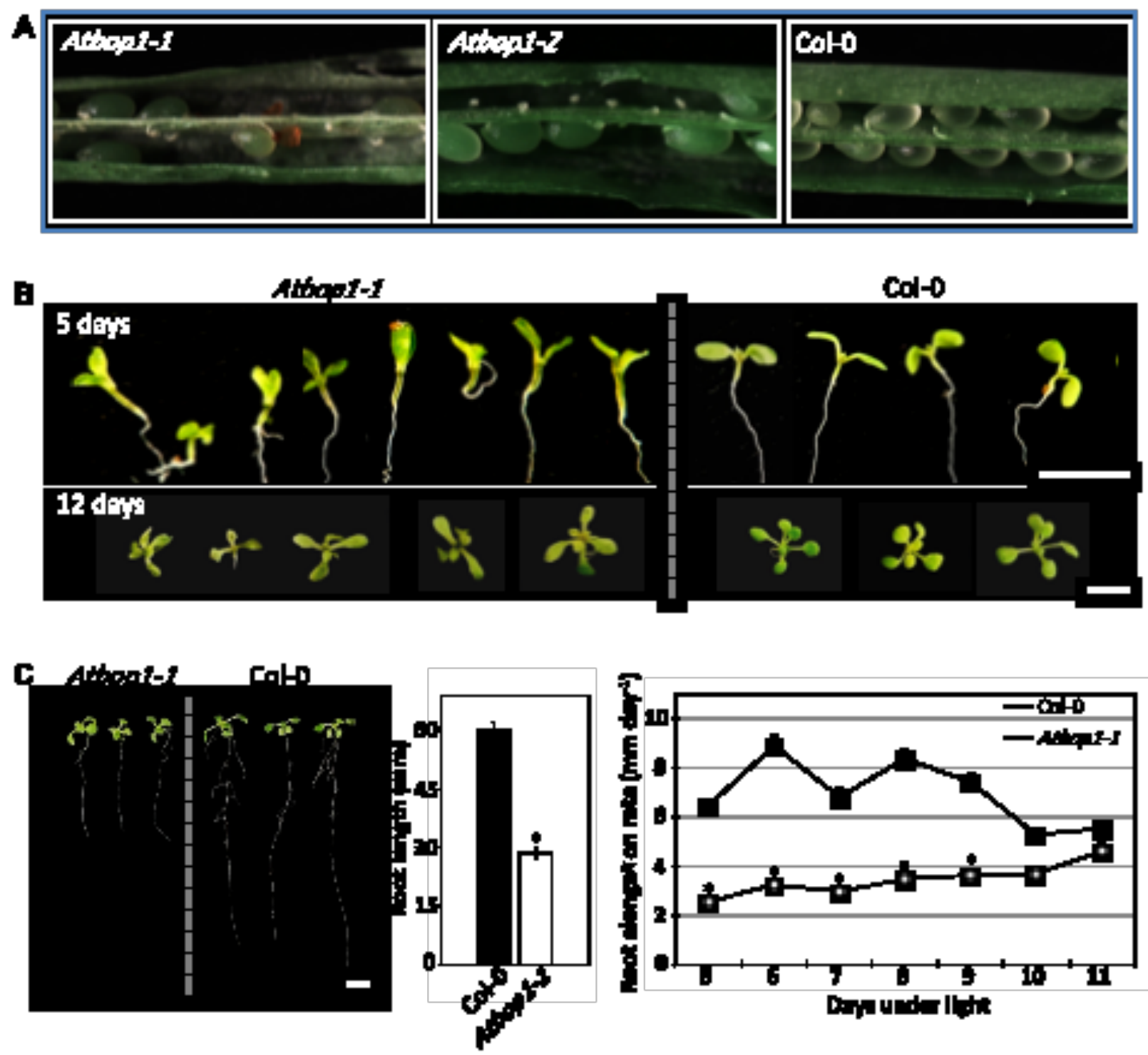

D

$E$
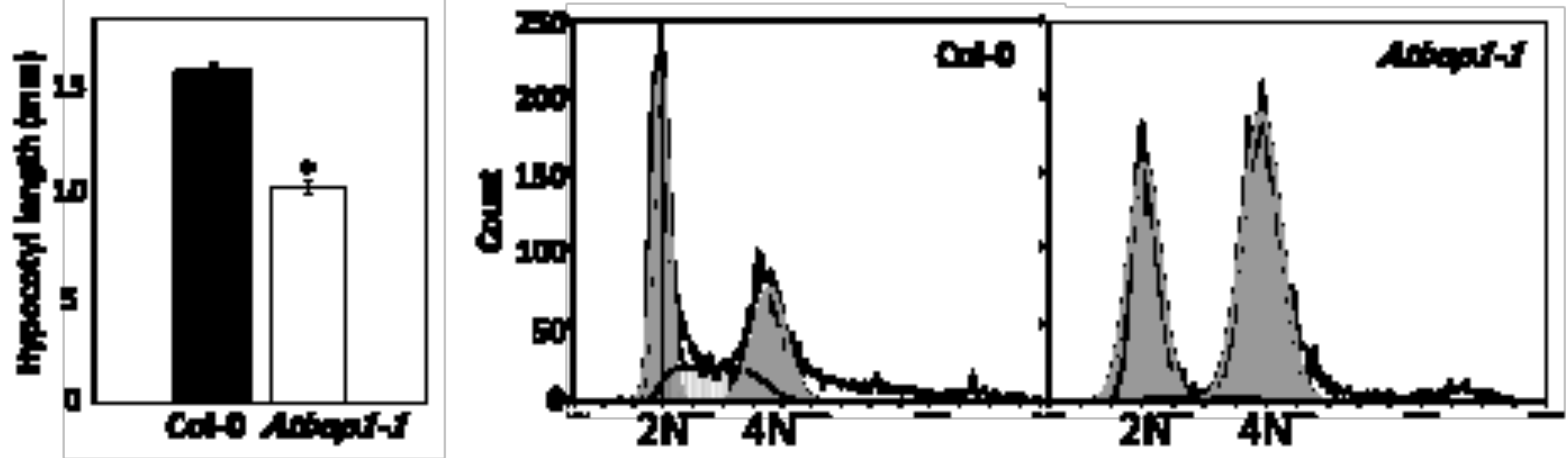